DOSSIÊ Trabalho e proletariado no século XXI

\title{
A "uberização" e o aprofundamento da flexibilização do trabalho
}

\author{
uberization and the deepening \\ of labor flexibility
}

\section{Euzébio Jorge silveira de sousa* Marcio ortiz meinberg**}

Foto: Marcelo Camargo - Agência Brasil

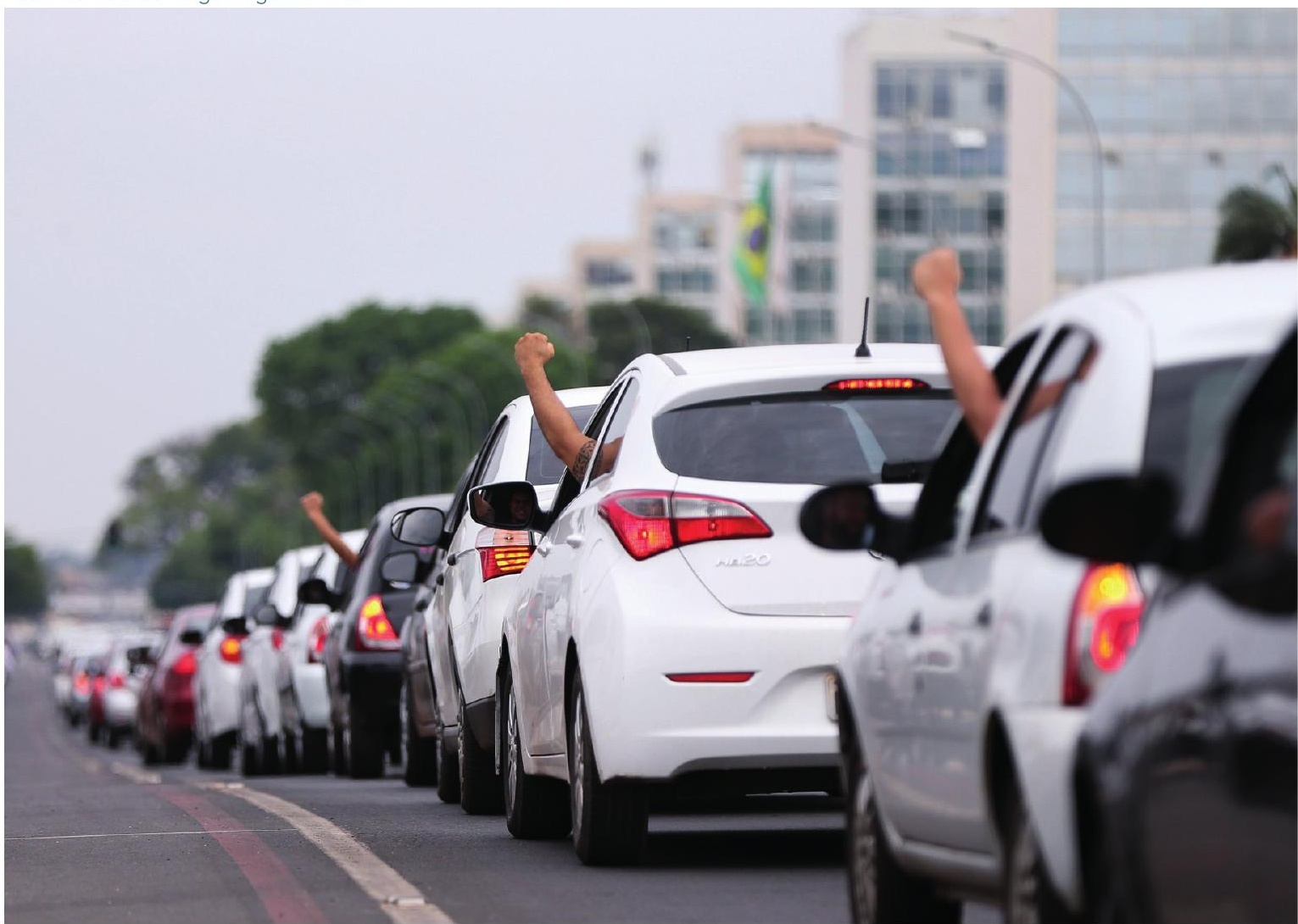

30/10/2017- Brasília - Motoristas de aplicativos fazem buzinaço em frente ao Congresso 


\section{RESUMO}

O objetivo deste artigo é conceituar o fenômeno da "uberização", além de expor suas justificativas e resultados. A “uberização" é um novo formato de utilização da força de trabalho, surgido da combinação das novas tecnologias originadas na terceira e quarta revoluções industriais com medidas de flexibilização trabalhista (defendidas pela economia neoclássica). Tal modelo sugere que a redução da interferência do Estado resultaria em crescimento econômico e maior eficiência produtiva (com redução do desemprego), o que motivou diversas reformas trabalhistas e flexibilização do aparato de proteção ao trabalho. As empresas que atuam por meio de trabalho "uberizado" encontraram no mercado de trabalho desestruturado uma oportunidade para ampliar sua rentabilidade expandindo a extração de mais-valia absoluta, mesmo em um setor que surge das novas tecnologias. As ocupações mais comuns da nova economia apresentam o mesmo conteúdo do trabalho de padrões de acumulação anteriores, como no caso dos motoristas de transporte individual e entregadores, no entanto, em condições mais precárias e sem direitos trabalhistas. A reforma trabalhista de 2017 não resultou em retomada do crescimento econômico e as empresas da economia de plataforma utilizam a crise e o desemprego para crescer.

Palavras-chave: Uberização; Precarização do trabalho; Economia de plataforma; Flexibilização dos direitos trabalhistas; Reforma trabalhista.

\section{ABSTRACT}

The purpose of this paper is to define the phenomenon of "uberization", as well as its justifications and its results. "Uberization" is a new way to use the workforce, based on the combination of new technologies from the 3 th and $4^{\text {th }}$ industrial revolutions, with labor easing measures (defended by the neoclassical economy). This a model suggests that reducing State interference would result in economic growth and greater resource efficiency (and unemployment drop), which motivated several labor reforms and easing of the labor protection apparatus. Companies that work through "uberized" labor have found an opportunity to increase their profitability in Brazilian inequality and in the historic disruption of the labor market, by expanding the extraction of absolute surplus value, even in a sector that arises from new technologies. The most common occupations in the new economy express the same content as the work of previous accumulation patterns, such as individual transport drivers and delivery personnel, however, in more precarious conditions and without labor rights. The 2017 labor reform did not result in economic growth and the platform economy companies are using the crisis and unemployment to grow.

Keywords: Uberization; Precarious work; Platform economy; Flexibility of labor rights; Labor reform. 


\section{INTRODUÇ̃̃o}

Desde a crise mundial de 2008 , as taxas de crescimento das economias mundiais despencaram se comparadas aos períodos anteriores. Além disso, antes mesmo da crise decorrente da pandemia de covid-I9, causada pelo novo coronavírus, desde 2019 diversos indicadores já demonstravam a existência de um novo período de recessão em todo o mundo.

Ao mesmo tempo, a Quarta Revolução Industrial resultou no surgimento de novas tecnologias, bem como em uma radical transformação de outros mercados já existentes, como telecomunicações e informática. O surgimento dos smartphones (telefones celulares de alta tecnologia, equiparáveis aos mais modernos computadores e integrados com a rede mundial de computadores) deu origem a todo um novo campo tecnológico, que são os aplicativos (softwares) para celular.

A combinação entre o período de crise econômica e as novas tecnologias da Quarta Revolução Industrial tem sido utilizada para gerar uma ampla transformação no mundo do trabalho. Como toda transformação de origem socioeconômica, seus reflexos na superestrutura estão sempre em disputa. Nesse sentido, o uso das novas tecnologias para enfrentamento da atual crise econômica do capitalismo pode ser feito para valorizar o trabalho vivo (facilitando e melhorando a vida das pessoas) ou para precarizar ainda mais o mercado de trabalho (ampliando a exploração e criando exércitos de pessoas economicamente dispensáveis).

No Brasil, o processo de "uberização" é uma clara evidência do uso das novas tecnologias para gerar precarização do trabalho. Tal processo, no entanto, só pode ocorrer com alterações na legislação trabalhista (muitas delas já realizadas ou em curso). Por outro lado, a luta dos trabalhadores, sindicatos e associações também pode reverter esse processo de precarização, pois a regulamentação do uso de tais tecnologias pode preservar as condições de vida dos trabalhadores.

\section{2. "UBERIZAÇ̃̃O"}

O termo "uberização" é uma referência à multinacional Uber Technologies Inc., que por meio de um aplicativo de smartphone "oferece" serviços de transporte, aproximando um motorista cadastrado do passageiro (semelhante a um serviço de táxi, ou, ainda, a uma carona remunerada). Nesse modelo de negócios, o passageiro e o motorista não se relacionam formalmente, pois o passageiro paga a tarifa do serviço para a empresa Uber, que por sua vez remunera o motorista. Semelhantes ao Uber, existem diversos outros aplicativos, com destaque para os chamados "aplicativos de entrega", como Rappi, Loggi, iFood e Uber Eats, que “aproximam” entregadores (de bicicleta, moto etc.) de estabelecimentos que desejam promover uma entrega para seus clientes (novamente, os pagamentos dos usuários são feitos para a empresa, que por sua vez remunera os entregadores). Há quem chame essas novas modalidades de "economia de plataforma". 
Assim, no mercado de trabalho, o conceito de "uberização" é utilizado para definir uma nova forma de utilizar, gerir e controlar a força de trabalho, com base em tecnologias da terceira e quarta revoluções tecnológicas. Esse novo formato de relações de trabalho associa-se a outros fenômenos do mundo do trabalho na contemporaneidade, como o trabalho just-in-time, o crowdsourcing, a difusão do trabalho amador produzindo riqueza abstrata e o gerenciamento do trabalho via algoritmo. O trabalhador uberizado é enquadrado como "empreendedor de si mesmo", o que sugere que ele negocia em condição de igualdade com empresas nacionais e transnacionais, sendo o único responsável por sua saúde física e mental, nível de remuneração e jornada de trabalho. De Stefano (20I6) realiza uma distinção entre dois tipos de ocupações mediadas por plataformas digitais, o crowdwork e o work on demand. $\mathrm{O}$ primeiro se refere às ocupações que são executadas on-line, permitindo que uma gama bastante heterogênea de tarefas possa ser executada por pessoas em diferentes lugares do mundo, permitindo à empresa uma grande flexibilidade de escolha quanto à procedência dos contratados. O segundo se refere a ocupações que são mediadas por plataformas digitais, mas as tarefas contratadas precisam ser executadas em uma região específica, como nas ocupações de transporte e serviços domésticos. Abílio (2019) apresenta o termo gig economy como uma categoria geral, capaz de abarcar um conjunto amplo de atividades comercializadas nas plataformas digitais. A categoria gig economy foi traduzida para o português como "economia dos bicos", pois é caracterizada por um setor que infla em períodos de crise econômica, gerando ocupações precárias que não possibilitam trajetórias estruturadas de carreira.

O trabalho uberizado é o produto não acabado de um processo de substantiva transformação no padrão de acumulação capitalista, amparado no esgotamento do fordismo, mudança no padrão tecnológico, fim do acordo de Bretton Woods, integração dos mercados em escala global e livre movimentação de capitais (OLIVEIRA, 20I5). O caminho de automação utilizado para implementar a economia de plataforma, longe de ser o único possível, foi induzido para gerar ganhos de produtividade amparados na eficiência dos mercados. Alicerçado no pensamento econômico novo-clássico e em outras variações do pensamento liberal, o neoliberalismo vê o desemprego como apenas o resultado de escolhas racionais de indivíduos calculando a melhor posição entre a desutilidade marginal do trabalho e a satisfação com o salário real (SOUSA, 20I7). Por mais anacrônico que possa parecer, na visão neoclássica não haveria explicação para o desemprego involuntário que não a rigidez e desequilíbrios dos mercados, gerada pela ineficiente interferência do Estado e de outras instituições como os sindicatos. Dessa forma, para os neoliberais, um dos elementos de interferência ineficiente do Estado (e, consequentemente, uma das causas do desemprego) são os direitos trabalhistas (e toda a legislação a eles relacionada).

Dessa forma, podemos identificar que o processo de "uberização" possui dois elementos constitutivos: o primeiro elemento é a nova tecnologia propriamente dita; o segundo elemento é o componente social, ou seja, a forma de utilização de tal tec- 


\section{O processo de "uberização" é uma clara} evidência do uso das novas tecnologias para gerar precarização do trabalho. Tal processo, no entanto, só pode ocorrer com alterações na legislação trabalhista (muitas delas já realizadas ou em curso). Por outro lado, a luta dos trabalhadores, sindicatos e associações também pode reverter esse processo de precarização, pois a regulamentação do uso de tais tecnologias pode preservar as condições de vida dos trabalhadores

nologia, que nesse caso tem sido a precarização do trabalho (que, segundo a teoria econômica neoclássica, resultaria em ampliação da taxa de ocupação). Ocorre que, no Brasil, a precarização do trabalho encontra obstáculos na legislação trabalhista, de modo que já há bastante tempo existe uma enorme pressão dos setores patronais pela flexibilização e desregulamentação do mercado de trabalho.

\section{ASCENSÃO E QUUEDA DOS DIREITOS TRABALHISTAS}

A história dos direitos trabalhistas é indissociável das lutas operárias por melhores condições de vida.

Durante a Primeira Revolução Industrial, os trabalhadores eram submetidos a jornadas extenuantes, recebiam salários irrisórios, moravam em ambientes insalubres e arriscavam-se constantemente a acidentes de trabalho, entre outras iniquidades. As fábricas eram apinhadas de homens, mulheres e crianças em condições degradantes. Tais injustiças decorriam da "livre" negociação entre patrões e empregados, como se estivessem em posição de igualdade.

Gradualmente os trabalhadores passaram a se organizar em sindicatos e a realizar atividades de resistência, como greves e sabotagem. Diante de tal pressão social, algumas leis começaram a ser aprovadas, estabelecendo jornada máxima e proibição do trabalho noturno infantil.

Como disse Henri Dominique Lacordaire, "entre os fortes e fracos, entre ricos e pobres, entre senhor e servo é a liberdade que oprime e a lei que liberta". E é nesse sentido que o direito trabalhista foi surgindo, de modo a reconhecer que a igualdade formal entre patrões e empregados é apenas um meio de perpetuar a desigualdade 
material entre eles. Ao reconhecerem a posição de hipossuficiência do trabalhador e garantindo sua proteção, os direitos trabalhistas tornam mais justa a relação entre patrões e empregados.

Há quem divida a história dos direitos trabalhistas em quatro etapas (GOMES, 20II): o primeiro período vai do final do século XVIII até o Manifesto do Partido Comunista (I848), de Marx e Engels; o segundo período, do Manifesto do Partido Comunista até a encíclica "Rerum novarum" (I89I), do papa Leão XIII; o terceiro período, da "Rerum novarum" até o final da Primeira Guerra Mundial (I9I8); e o quarto período, do final da Primeira Guerra Mundial até os nossos dias. É importante esclarecer que essa classificação é bastante eurocentrada, tendo em vista que cada país possui uma evolução própria dos direitos trabalhistas.

No caso do Brasil, desde os primórdios do século XX os trabalhadores urbanos já começam a se organizar e a travar batalhas por melhores condições de vida e trabalho. Dois exemplos de tais lutas são a Greve Geral de I9I7, ocorrida em São Paulo, e a fundação do Partido Comunista do Brasil, em 1922. Durante tal período, qualquer legislação que eventualmente abordasse a questão do trabalho o fazia sob a ótica liberal, pressupondo que o patrão e o empregado estariam em posição de igualdade para negociar suas condições.

A partir da Revolução de I930, o Brasil passa por rápidas transformações econômicas, sociais e políticas, intensificando-se o processo de industrialização. Em paralelo, a Crise de 1929 (o crash da Bolsa de Nova York) derrotou o paradigma liberal de não intervenção do Estado na economia, de forma que muitos países passaram a adotar novas experiências econômicas. Nesse cenário, foram criadas no Brasil diversas normas jurídicas de proteção aos trabalhadores, com destaque para as constituições de 1934 e 1937 (ainda que autoritária) e diversas leis que posteriormente foram reunidas na Consolidação das Leis do Trabalho (CLT), em I943. É importante ressaltar que naquele momento os direitos trabalhistas eram uma exclusividade dos trabalhadores urbanos, de modo que os trabalhadores do campo ainda permaneceriam desprotegidos por muitas décadas.

Com a continuidade da industrialização do Brasil, o processo de conquista de direitos trabalhistas segue por todo o século XX (mesmo durante as duas ditaduras), atingindo seu ápice com a Constituição Federal de I988. A Constituição de I988 representou uma grande conquista, pois garantiu direitos trabalhistas para os trabalhadores do campo (a única categoria que permaneceu parcialmente desprotegida foi a dos trabalhadores domésticos, cuja inclusão efetiva só viria a ocorrer com a emenda constitucional no 72/20I3, durante o Governo Dilma Rousseff) (BALTAR, 20I8).

Na década de 1970, com o declínio do paradigma keynesiano, as teorias neoclássicas retomaram força em todo o mundo e, gradualmente, chegaram ao Brasil (em especial a partir dos anos I990). O capital, que ficara relativamente contido durante os anos de ouro do capitalismo, buscou se libertar de quaisquer amarras. A valorização do valor deveria ocorrer sem obstáculos de Estados nacionais, limites tecnológicos ou 
Ao trabalhador individual, tido como empreendedor de si

mesmo, resta a incerteza sobre quantas horas terá de trabalhar por dia, e se conseguirá atingir rendimentos que lhe garantam a subsistência. Imbuído da crença de que não possui patrão, esse trabalhador se sentirá responsável por seu próprio sucesso ou fracasso, o que pode Ihe suscitar um comportamento competitivo, criando obstáculos para a organização de trabalhadores em busca de melhores condições de trabalho ou de mudanças sociais mais profundas

legislações trabalhistas e ambientais. A indissociabilidade entre capital financeiro e produtivo originou inovações na dinâmica de rotação do capital, ao articular extensas cadeias globais de valor, que ignoravam projetos e fronteiras nacionais, com uma rápida expansão do capital fictício. A flexibilidade e plasticidade das tecnologias de comunicação e informação possibilitaram a descentralização da produção, com inovações no gerenciamento e busca por países com menores custos com trabalho e maior mobilidade para os capitais. A busca por uma acumulação sem barreiras estabelecia parâmetros de conduta aos países periféricos ansiosos por receber capital volátil e temperamental, o que produzia pressões por aplicações do Consenso de Washington.

O processo de flexibilização do trabalho faz parte de uma constelação de fenômenos que busca reduzir os obstáculos para a acumulação. As cadeias produtivas globais se utilizam de subcontratações a fim de externalizar setores com menor rentabilidade e com maior sujeição às legislações locais. A terceirização apresenta-se como uma versátil forma de utilizar a força de trabalho, eliminando as obrigações de 
lidar diretamente com as imprecisões e vicissitudes do trabalho vivo. Trata-se apenas de uma inovação organizacional que mantém o mesmo conteúdo do trabalho, sem submeter as empresas contratantes ao desconforto de manter um número de trabalhadores superior ao estritamente necessário. A ideologia do empreendedorismo permite um passo adiante na flexibilização, ao utilizar a desestruturação do mercado de trabalho e a insatisfação do trabalhador com sua subordinação ao patrão para destruir o consenso sobre a assimetria entre capital e trabalho, estabelecendo a ordem dirigida pela eficiência dos mercados. Na prática se verifica a transferência dos riscos inerentes ao negócio a um trabalhador individual, em vez de transferi-los à empresa terceirizada, que gera ocupações precárias, mas com garantia mínima de direitos trabalhistas. Ao trabalhador individual, tido como empreendedor de si mesmo, resta a incerteza sobre quantas horas terá de trabalhar por dia, e se conseguirá atingir rendimentos que lhe garantam a subsistência. Imbuído da crença de que não possui patrão, esse trabalhador se sentirá responsável por seu próprio sucesso ou fracasso, o que pode lhe suscitar um comportamento competitivo, criando obstáculos para a organização de trabalhadores em busca de melhores condições de trabalho ou de mudanças sociais mais profundas.

No Brasil, a pressão pela flexibilização das leis trabalhistas veio sendo gestada durante muitos anos, com intensa propaganda de ideias neoliberais, apresentando os direitos trabalhistas como "ultrapassados" e acusando-os de "encarecer" a mão de obra e gerar desemprego.

A partir da crise econômica que se seguiu ao golpe contra a presidenta Dilma Rousseff (em 20I5 e 20I6), pôs-se em marcha uma vigorosa campanha de ataques aos direitos trabalhistas. Em 2017 foi feita a reforma trabalhista do Governo Temer (lei no I3.467/I7), que atacou diretamente os sindicatos — tornando opcional a contribuição sindical ${ }^{1}$, dispensando a presença deles na homologação das rescisões ${ }^{2}$ e enfraquecendo sua representação nas empresas ${ }^{3}$ — e violou diversos direitos: excluiu diversas atividades da jornada de trabalho ${ }^{4}$, incluindo o deslocamento ${ }^{5}$, dificultou o acesso às horas extras, por causa do banco de horas ${ }^{6}$, reduziu o horário mínimo para refeições ${ }^{7}$, dificultou o acesso à Justiça do Trabalho ${ }^{8}$, permitiu o fracionamento do período de gozo de férias ${ }^{9}$ e prejudicou a proteção às gestantes ${ }^{10}$, entre outros ataques. Apesar disso, o tema central da lei $\mathrm{n}^{\circ} \mathrm{I3} .467 / \mathrm{I} 7$ era a desregulamentação do trabalho, o que foi feito por meio

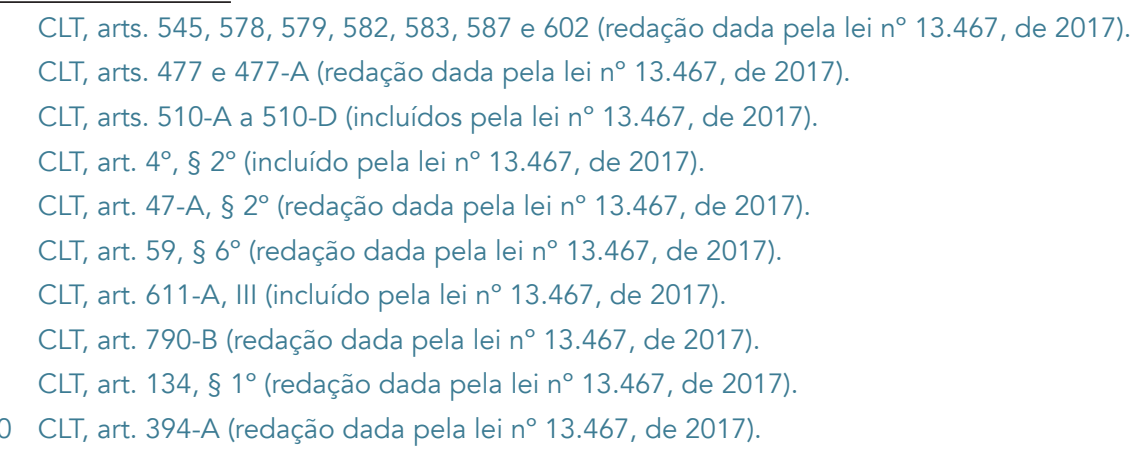


do conceito de prevalência do negociado sobre o legislado ${ }^{\mathrm{II}}$, permitindo terceirizações irrestritas $^{12}$ (inclusive da atividade principal) e trabalho intermitente ${ }^{13}$ e reduzindo a proteção ao trabalhador autônomo exclusivo ${ }^{14}$. Ainda em 20I7, o presidente Michel Temer editou a medida provisória $\mathrm{n}^{\circ} 808 / \mathrm{I} 7$, com diversas alterações da própria reforma trabalhista, mas a referida MP perdeu validade em 24 de abril de 2018.

Posteriormente, em 2019, o Governo Bolsonaro promoveu novos ataques aos direitos trabalhistas, por meio da medida provisória no 88I/20I9 ("MP da Liberdade Econômica” $)^{15}$, que foi convertida na lei $\mathrm{n}^{\mathrm{o}}$ 13.874/19. A minirreforma trabalhista do Governo Bolsonaro aprofundou a flexibilização do trabalho, prejudicando a regulamentação e a fiscalização do trabalho (por exemplo, torna opcional o registro de ponto $^{16}$ e acaba com o eSocial ${ }^{17}$ ). Convenientemente, essa medida foi apresentada como um estímulo ao empreendedorismo.

Ainda em 20I9, novo ataque foi realizado ao direito do trabalho, com a criação do Contrato de Trabalho Verde e Amarelo pela medida provisória n 905/19. Tal contrato, destinado a jovens de 18 a $29 \operatorname{anos}^{18}$ que nunca houvessem tido vínculo empregatício $^{19}$, estabelecia uma remuneração mensal de até I,5 salário mínimo ${ }^{20}$ e implicava a renúncia a diversos direitos trabalhistas, como a redução do depósito do Fundo de Garantia do Tempo de Serviço (FGTS) ${ }^{21}$, da multa fundiária ${ }^{22}$ e do valor do adicional de periculosidade ${ }^{23}$. Além disso, a MP no 905/19 estabeleceu a possibilidade de trabalho aos domingos e feriados para todas as categorias profissionais (e não apenas para quem estivesse sob o Contrato de Trabalho Verde e Amarelo ${ }^{24}$, aumentou a jornada de trabalho dos bancários ${ }^{25}$, excluiu os sindicatos das negociações da Participação nos Lucros e Resultados (PLR) ${ }^{26}$, reduziu os juros de mora em ações trabalhistas ${ }^{27}$ e revogou a previsão de acidente no trajeto (o acidente ocorrido no trajeto do emprego deixa

11 CLT, arts. 611-A, 611-B, 614 e 620 (redação dada pela lei n 13.467, de 2017).

12 Lei n 6.019, de 1974, art. 4-A (redação dada pela lei n 13.467, de 2017).

$13 \mathrm{CLT}$, art. 443, § $3^{\circ}$ (incluído pela lei $n^{\circ} 13.467$, de 2017).

14 CLT, arts. 442-B e 452-A (incluídos pela lei n 13.467, de 2017).

15 Durante a tramitação da MP, houve tentativa de retirada de diversos outros direitos trabalhistas, como o descanso semanal remunerado aos domingos e a obrigatoriedade das Comissões Internas de Prevenção de Acidentes (Cipas). Graças à pressão dos trabalhadores, esses pontos não foram aprovados naquela ocasião.

16 CLT, art. 74 (redação dada pela lei nº 13.874, de 2019).

17 Lei n 13.874, de 2019, art. 16.

$18 \mathrm{MP} \mathrm{n}^{\circ} 905$, de 2020 , art. $1^{\circ}$, caput.

$19 \mathrm{MP} \mathrm{n}^{\circ} 905$, de 2020, art. $1^{\circ}$

$20 \mathrm{MP} \mathrm{n}^{\circ}$ 905, de 2020, art. $3^{\circ}$.

$21 \mathrm{MP} \mathrm{n}^{\circ} 905$, de 2020, art. $7^{\circ}$.

$22 \mathrm{MP} \mathrm{n}^{\circ} 905$, de 2020, art. $6^{\circ}$, § $1^{\circ}$

$23 \mathrm{MP} \mathrm{n}^{\circ}$ 905, de 2019, art. 15, § $3^{\circ}$ e $4^{\circ}$.

24 CLT, art. 68 (redação dada pela MP nº 905, de 2019).

25 CLT, art. 224 (redação dada pela MP nº 905, de 2019).

$26 \mathrm{MP} \mathrm{n}^{\circ}$ 905, de 2019, art. 48 (redação dada pela MP nº 905, de 2019).

27 Lei n 8.177, de 1991, art. 39, § $1^{\circ}$ (redação dada pela MP n 905, de 2019). 
de ser considerado acidente de trabalho $)^{28}$. Novamente por ampla articulação dos sindicatos e dos partidos políticos comprometidos com a luta dos trabalhadores, a MP no 905/20 perderia sua validade sem conversão, de modo que o presidente da República se viu obrigado a revogá-la por meio da medida provisória ${ }^{\circ}$ 955/20.

Eis que, em 2020, sob a justificativa de adotar medidas para enfrentamento da pandemia do novo coronavírus (agente da covid-ı), o Governo Bolsonaro editou a medida provisória no 927/20, com mais flexibilizações de direitos trabalhistas. O principal ataque havia sido a possibilidade de suspensão do contrato de trabalho por até quatro meses $^{29}$, mas a repercussão da medida foi tão negativa que no dia seguinte o presidente foi obrigado a recuar (a MP no 928/20 revogou a medida). No entanto, outras violações permaneceram, entre elas a exclusão dos sindicatos nas negociações individuais, que passaram a prevalecer sobre quaisquer outros instrumentos normativos (legais e/ou negociais) ${ }^{30}$, a suspensão de exigências administrativas de segurança e saúde no trabalho ${ }^{31}$, a suspensão de exames médicos e treinamentos periódicos ${ }^{32}$, a possibilidade de contratação unilateral de banco de horas ${ }^{33}$, a permissão para as empresas anteciparem as férias dos trabalhadores sem que eles tenham direito a negociação ${ }^{34}$ e para adiarem o pagamento do adicional de um terço do salário, referente às férias, até o pagamento do $13^{\circ}$ salário $^{35}$.

Cerca de dez dias depois, Bolsonaro editou nova medida provisória ( $n^{\circ} 936 / 20$ ), pela qual retomou a possibilidade de suspensão temporária do contrato de trabalho ${ }^{36}$ ou redução proporcional de salários e da jornada de trabalho em até $70 \%{ }^{37}$, sempre em negociação individual, sem intermediação do sindicato. Tanto a MP no 927/20 quanto a MP nº 936/20 foram apresentadas sob a justificativa de proteger o emprego.

\section{O USO DAS NOVAS TECNOLOGIAS PARA A PRECARIZACÃO DO TRABALHO}

A associação de tecnologias da terceira e quarta revoluções tecnológicas permitiu a criação de plataformas que estabelecem novas formas de contratação, gerenciamento e condicionamento para o trabalho. A produção e processamento de um grande volume de dados permitiram a construção de dispositivos de gerenciamento via algoritmo, em que o trabalhador é enquadrado em uma dinâmica gamificada que determina a rotina e intensidade do trabalho por meio de castigos e bonificações. Para deixar claro que não se trata de um entretenimento, o enquadramento do trabalha-

\footnotetext{
28 Lei $n^{\circ} 8.213$, de 1991, art. 21, IV, d.

$29 \mathrm{MP} \mathrm{n}^{\circ}$ 927, de 2020, art. 18.

$30 \mathrm{MP} \mathrm{n}^{\circ}$ 927, de 2020, art. $2^{\circ}$.

$31 \mathrm{MP} \mathrm{n}^{\circ} 927$, de 2020, art. $3^{\circ}, \mathrm{VI}$.

$32 \mathrm{MP} \mathrm{n}^{\circ}$ 927, de 2020, arts. 15 e 16.

33 MP n 927, de 2020, art. 14.

$34 \mathrm{MP} \mathrm{n}^{\circ} 927$, de 2020, arts. $6^{\circ}$ a 10.

$35 \mathrm{MP} \mathrm{n}^{\circ}$ 927, de 2020, art. $8^{\circ}$.

$36 \mathrm{MP} \mathrm{n}^{\circ}$ 936, de 2020, arts. $3^{\circ}$, III, e $8^{\circ}$

$37 \mathrm{MP} \mathrm{n}^{\circ} 936$, de 2020, arts. $3^{\circ}, 11$, e $7^{\circ}$.
} 
dor nessa lógica ocorre gerando remunerações variáveis, o que pode comprometer sua condição de subsistência. A precariedade material dos trabalhadores e a desestruturação do mercado de trabalho são dispositivos desejáveis ao funcionamento das plataformas, dada a programação dos algoritmos para reduzir remunerações quando se verifica excesso de oferta de trabalho.

Respaldadas pela citada teoria neoclássica de eficiência dos mercados e nas já experimentadas formas de terceirização, as empresas ligadas à economia de plataforma se apresentam como meras intermediárias entre ofertantes e demandantes dos serviços, o que as exime de arcar com direitos trabalhistas e condições adequadas de trabalho. As empresas negam qualquer tipo de vínculo empregatício ou subordinação do trabalhador, ainda que sejam elas que determinam o valor da remuneração, a distribuição das tarefas e as regras para sua execução. Os trabalhadores recebem apenas pelas tarefas executadas, não importando o tempo que tenham ficado à disposição da plataforma e se terão no final do mês uma remuneração não inferior ao salário mínimo legal. A aplicação de metodologias de gamificação do trabalho cumpre o papel de estabelecer remunerações que variarão a depender da capacidade do "jogador" de cumprir as tarefas solicitadas, ainda que as regras do jogo variem durante a partida.

Assim, pode ser constatado que as empresas da gig economy possuem flexibilidade máxima em duas circunstâncias determinantes para o processo de valorização: a de pagar os salários que desejarem e a de contratar estritamente os minutos que quiserem utilizar da força de trabalho. As empresas não garantem remunerações com valor equivalente à cesta de subsistência do trabalhador, o que o obriga a buscar um leque diversificado de atividades remuneradas, que serão executadas simultaneamente. Já o chamado work on demand estabelece uma dinâmica na qual o trabalhador não sabe qual será sua remuneração no final do dia (DE STEFANO, 20I6), visto que a remuneração variável transfere aos trabalhadores os riscos inerentes à atividade capitalista. Nos períodos de piora nos indicadores econômicos, além de haver um número maior de pessoas ofertando trabalho na plataforma, dada a elevação do desemprego, as remunerações declinam. Ainda que a empresa afirme não contratar o trabalhador, ela está apta a desligá-lo sem precisar arcar com qualquer custo adicional, não precisando nem mesmo informar os motivos da despedida ao trabalhador ou a uma instituição pública.

O avanço das ocupações de plataforma também foi responsável por eliminar um elevado número de ocupações intermediárias de gerenciamento, pois é desenvolvido um modelo automatizado de controle do trabalhador que conta com o trabalho não remunerado dos usuários nas avaliações. Sem possuir orientações claras de conduta e por critérios não objetivos, os trabalhadores são observados todo o tempo pela empresa e avaliados pelos usuários, atribuindo-se diferentes patamares de remuneração e credibilidade aos prestadores dos serviços. Segundo Abílio (2019), as avaliações dos usuários geram dispositivos de certificação privada, que busca prescindir de sistemas públicos, assim como ocorre com a certificação de taxistas e entregadores 


\section{Note-se que a precarização em si não é causada pela tecnologia, mas a tecnologia é utilizada como ferramenta da visão neoclássica da economia para criar essas "novas" modalidades de trabalho}

dos correios. A inexistência de uma certificação pública é um dos indícios do que foi chamado de trabalho amador por Van Doorn, em 20I7, definição que pode ser atribuída tanto pela inexistência de normas e ou regulações públicas quanto por se tratar de vínculos tão fluidos que os trabalhadores podem estar envolvidos em diferentes tipos de ocupações concomitantes para garantir um rendimento mínimo.

Para que essa dinâmica funcione é necessário um enorme número de pessoas ofertando e demandando os serviços de um número pequeno de empresas. O termo crowdsourcing se refere a essa multidão que gera dados sobre a avaliação dos trabalhadores, as demandas locais e as necessidades de deslocamento dos prestadores de serviços. No modelo de negócio implementado pelas empresas de plataforma, é necessária uma multidão de pessoas dispostas a ofertar trabalho.

Note-se que a precarização em si não é causada pela tecnologia, mas a tecnologia é utilizada como ferramenta da visão neoclássica da economia para criar essas "novas" modalidades de trabalho. $\mathrm{O}$ uso das aspas refere-se especialmente ao caso dos aplicativos de entrega (mas não só a eles), uma vez que as posições de trabalho dos ciclistas e motociclistas já existiam muito antes da criação de tais aplicativos e das empresas desenvolvedoras (Loggi, Rappi, iFood, Uber Eats etc.), porém eram posições de trabalho formal, regidas pela CLT. Tais empresas, em vez de criar novas vagas de trabalho, inicialmente disputaram diretamente o mercado de entregas, oferecendo preços mais baixos que os praticados pelas tradicionais empresas de entrega já existentes, levando-as à falência (prática conhecida como dumping). Após a dominação dos mercados, tais empresas então prosseguiram com o rebaixamento dos salários dos entregadores, que, agora sem alternativa fora da "economia de plataforma", são obrigados a submeter-se às novas condições (além dos salários reduzidos, esses trabalhadores não possuem vínculo formal, ficando desprotegidos em caso de acidentes e dispensa, além de não terem uma jornada máxima de trabalho estipulada e não receberem o pagamento do adicional de horas extras, entre outros direitos trabalhistas negados).

Enfim, contrariando a hipótese de eficiência e equilíbrio dos mercados, a uberização avança promovendo um processo de concentração e centralização de capitais. No Brasil os ganhos de competitividade em atividades de entregas por motofretistas e transporte individual são derivados da inexistência de regulação trabalhista, salá- 
rios inferiores ao mínimo legal, jornadas superiores às 44 horas semanais previstas na CLT e não pagamento de encargos. As diferentes estruturas de custos entre as novas empresas de plataforma e as tradicionais empresas de transporte não estão restritas às disparidades tecnológicas, mas também às diferentes regras regulatórias de cada segmento, que permitem que as empresas da gig economy ampliem a extração de mais-valia e se esquivem de contribuições para manter o Estado. O citado processo gera um movimento de maior oligopolização do setor, reduzindo as alternativas de ocupação dos trabalhadores, o que possibilita reduções mais profundas das suas remunerações.

Tais práticas nefastas, contudo, podem ser bloqueadas por meio da legislação, seja a trabalhista (ao regulamentar o trabalho dos "uberizados", impedindo o achatamento salarial, reconhecendo o vínculo empregatício ou obrigando o estabelecimento de direitos alternativos similares aos dos trabalhadores formais), seja a legislação concorrencial (que deveria impedir a dominação de mercados por essas empresas que praticam preços abaixo do custo, o que constitui infração da ordem econômica) ${ }^{38}$.

\section{MERCADO DE TRABALHO NO BRASIL E UBERIZACÃO}

Dois movimentos complementares são observados no mercado de trabalho no Brasil: o primeiro diz respeito ao processo de precarização e ampliação da taxa de participação da força de trabalho, oriundo do aprofundamento da crise, da ampliação da desocupação e da redução da renda das famílias; o segundo é um movimento de caráter estrutural e subordinado ao atual estágio da acumulação e avanço das forças produtivas. Ao passo que a crise econômica se aprofunda, são realizadas transformações institucionais e econômicas que oferecem maior liberdade à mobilidade dos capitais e à utilização da força de trabalho (SOUSA, 20I8). A prevalência do mercado sobre o Estado - ou qualquer outra forma de regulação - se apresenta como uma alternativa viável à crise econômica, uma vez que essa ideologia professa a eficiência dos mercados, apontando o trabalho como uma mercadoria qualquer e propalando uma suposta igualdade de condições de negociação entre trabalhadores e empresários (FERREIRA, 20I4).

De acordo com tal corrente de pensamento, os trabalhadores desempregados optam pela desocupação a fim de maximizar sua utilidade (MIGLIOLI, 1979). Tais compreensões econômicas advindas do pensamento monetarista e novo-clássico contribuíram para a busca de tecnologias e arranjos institucionais que eliminam qualquer porosidade do trabalho, externalizam riscos inerentes à atividade capitalista e promovem a remuneração por demanda. As características citadas nunca foram estranhas à dinâmica de rotação do capital no Brasil, dado que as ocupações que remuneram por tarefas executadas e com salários que não garantem adequadamente os custos de subsistência se apresentam como regra em vários setores e subsetores, como a indústria têxtil e o setor agrícola. Porém, a funcional interação entre os seto- 


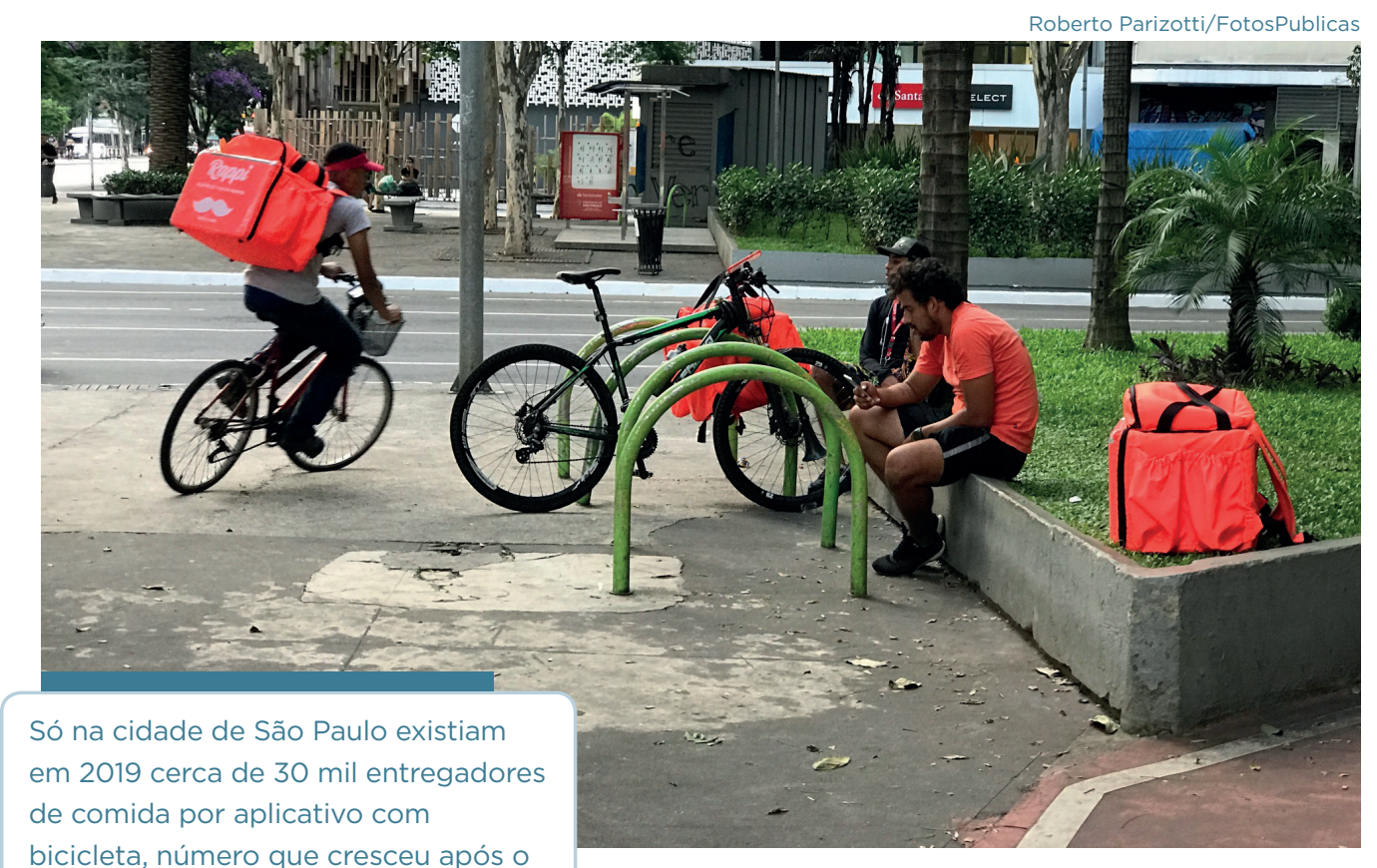

bicicleta, número que cresceu após o

aprofundamento da crise

res atrasados e modernos é compatível com a nova economia de plataforma e com o permanente excesso de força de trabalho no Brasil. A reforma trabalhista e a regulamentação da terceirização em 2017 cumpriram um papel determinante ao flexibilizar o mercado de trabalho, regulamentar uma multiplicidade de vínculos e autorizar a terceirização e "pejotização" quase irrestritas. As mudanças foram tão profundas que foi debatido alterar a definição de trabalho escravo (MENDONÇA, 20I7), a fim de permitir formas ainda mais rudimentares de trabalho e remuneração (SOUSA, 20I8).

Em meio à crise econômica, os jovens das famílias mais pobres encontram oportunidade de acesso ao mercado de trabalho nos setores mais precários da economia de plataforma, como o de entrega de comida por aplicativo. Segundo Abílio (2019), só na cidade de São Paulo existiam em 2019 cerca de 30 mil entregadores de comida por aplicativo com bicicleta, número que cresceu após o aprofundamento da crise. Além de os dados sobre os entregadores serem demasiadamente fluidos, variando diretamente com alterações da taxa de desocupação, as empresas que contratam tais serviços não disponibilizam os dados para não serem responsabilizadas pelo não cumprimento dos mais elementares direitos da já flexibilizada legislação trabalhista. Vale destacar que as entregas por aplicativo por empresas como iFood, Rappi e Uber Eats ocorrem de distintas formas, seja com bicicleta própria ou alugada, a pé ou de cadeira de rodas (LEMOS, 2020). Independentemente dos meios, o que fica explícito é a absoluta indiferença das empresas com as condições de trabalho de seus funcionários.

Segundo uma pesquisa da Associação Brasileira do Setor de Bicicletas (ALIANÇA BIKE, 20I9), 75\% dos entregadores por bicicleta tinham até 27 anos de idade, sendo 
50\% com menos de 23 anos, o que indica que essa é uma nova modalidade de ocupação de início de carreira. Esses jovens são de famílias mais pobres, o que pode ser evidenciado pelo fato de $40 \%$ terem cursado apenas até o ensino fundamental. A maioria dos entregadores residem nas periferias da cidade e sofrem um elevado desgaste físico só para chegar até os locais de entrega, isso quando não optam por dormir na rua para estar no local das entregas em horário adequado (JAKITAS, 2019). Assim como ocorre nas periferias de São Paulo e nas ocupações mais degradantes, a maioria dos entregadores são negros (7I\%). Uma evidência da ampliação da mais-valia em um momento de peculiar avanço das forças produtivas é que esses novos trabalhadores trabalham muitas horas e recebem baixíssimos salários. Segundo a pesquisa, $57 \%$ dos entregadores trabalhavam 7 dias por semana, e $24 \%$ trabalhavam 6 dias semanais. Metade dos trabalhadores realizavam entregas mais de io horas por dia e I/4 possuía jornadas de trabalho que ultrapassavam I2 horas. É sabido que essa ocupação, além de oferecer elevados riscos à saúde dos jovens, também impõe limites físicos ao prolongamento da jornada, limites que se tornam mais restritivos conforme o trabalhador envelhece, o que reduz seus rendimentos. Ainda que boa parte dos entregadores trabalhassem mais de Io horas por dia, o rendimento médio nesse setor era, em 20I9, de R \$ 992 ao mês, quantia 4,5\% inferior ao salário mínimo então vigente. Se forem consideradas jornadas de 44 horas semanais, o salário desses trabalhadores era inferior a $\mathrm{R} \$ 600$ por mês.

Um indício relevante de que as empresas promovem externalização dos custos e riscos da atividade é que nas ocupações de plataforma os trabalhadores são obrigados a prover parte considerável dos meios de produção. Ainda segundo a pesquisa da Aliança Bike, 3I\% dos trabalhadores compraram a bicicleta que utilizam no trabalho e $27 \%$ reformaram a que já tinham com essa finalidade; $30 \%$ precisaram adquirir um celular e $67 \%$ pagaram pela mochila térmica usada nos serviços.

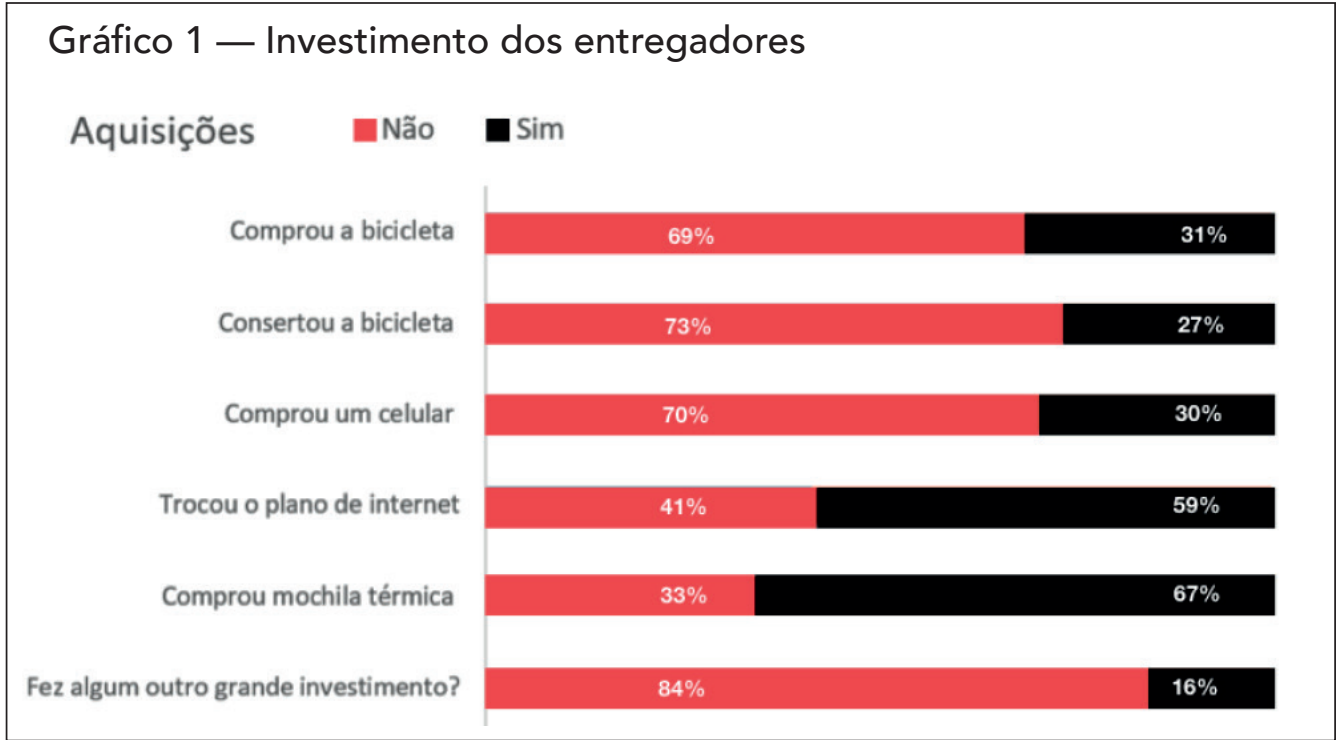

Fonte: Aliança Bike (2019, p. 14) 


\section{A chamada "economia de plataforma" foi aplicada combinando as novas tecnologias e a precarização do trabalho. Porém, os resultados até então demonstrados não indicam qualquer aumento das posições de trabalho nem um estímulo ao crescimento econômico}

Outro dado apresentado foi a opinião dos entregadores sobre as vantagens de realizar entregas por aplicativos. A opção "emprego rápido sem processo seletivo" foi a mais votada, o que está relacionado com o fato de $59 \%$ estarem desempregados antes de começarem a realizar as entregas. Em segunda posição apareceu "flexibilidade de horário", o que é curioso, pois a jornada média dos entregadores era de io horas diárias. No entanto, essa resposta pode estar relacionada com a sexta opção mais votada, "não ter patrão", ao representar a difusão de uma cultura de empreendedorismo, que se propaga entre os jovens, discurso que assume diferentes formas, seja por meio da autoajuda ou da teologia da prosperidade. Independentemente da forma, busca-se consolidar um discurso que permite uma acumulação sem barreiras, transferindo aos trabalhadores os riscos da produção capitalista. Ao se gerar maior liberdade ao capital e desproteção ao trabalho, é possível utilizar as oscilações da atividade econômica para transferir para os trabalhadores os efeitos deletérios das crises (SOUSA, 20I8). Os algoritmos da economia de plataforma estão calibrados para reduzir a remuneração dos trabalhadores sempre que ocorrer ampliação de oferta de trabalho e elevar a dos que não participarem de paralisações.

O quadro em 2020 é mais grave que o observado nos últimos anos, segundo estudo da Rede de Estudos e Monitoramento da Reforma Trabalhista (Remir-Trabalho). De acordo com a pesquisa, 60,3\% dos entrevistados afirmaram ter os rendimentos reduzidos após o início da pandemia e 27,6\% afirmaram não ter identificado variação dos rendimentos; $77,4 \%$ dos entrevistados trabalhavam ao menos 6 dias por semana, em 2 períodos do dia ininterruptos durante a pandemia. Ficou explícito que os algoritmos são programados para majorar os lucros em períodos de crises econômicas, tendo em vista empresas como a Rappi, que, só em março de 2020, ampliou em $300 \%$ o número de inscritos, sendo que em fevereiro do mesmo ano tinha ampliado seu faturamento em 30\%. Em meio à crise humanitária e econômica, as empresas pararam de divulgar o crescimento de seus faturamentos, possivelmente para evitar os constrangimentos relacionados à redução das remunerações dos trabalhadores. 
Em suma, ao contrário do que foi alardeado, a precarização do trabalho por meio da flexibilização das leis trabalhistas não resultou em aumento da taxa de ocupação. Segundo dados do IBGE (ABDALA, 20I8), o nível de desemprego era de I2,7\% em 2017 (início das reformas trabalhistas) e de II,6\% em fevereiro de 2020 (antes da pandemia) (BARROS, 2020). Ou seja, fica difícil sustentar que a retirada dos direitos trabalhistas produziu os resultados econômicos propostos. Por outro lado, a perda de qualidade dos empregos é patente.

\section{CONSIDERACִÕES FINAIS}

A crise econômica mundial e as novas tecnologias colocam diversos desafios para o desenvolvimento de todos os países. A proposta dos economistas de matriz neoclássica pressupõe que a diminuição da intervenção do Estado resultaria em crescimento (da economia e do emprego), pois haveria a total racionalização dos recursos. Medidas nesse sentido foram implementadas no Brasil, em especial no campo do direito do trabalho, com muita força a partir de 2017.

Nesse sentido, a chamada "economia de plataforma" foi aplicada combinando as novas tecnologias e a precarização do trabalho. Porém, os resultados até então demonstrados não indicam qualquer aumento das posições de trabalho nem um estímulo ao crescimento econômico. Por sua vez, os trabalhadores que se submeteram a esse novo "mercado de trabalho" assumiram posições bastante degradantes, com quase nenhuma segurança jurídica, ausência de direitos trabalhistas, salários baixos e jornadas extenuantes.

O uso da tecnologia não precisa, necessariamente, ser aliado à precarização do trabalho. Pelo contrário, a defesa das leis trabalhistas, seja pela revogação das flexibilizações ocorridas, seja pela introdução de novas medidas de proteção ao trabalhador, é uma possibilidade para a retomada do crescimento e do emprego.

* Mestre em Economia pela Pontifícia Universidade Católica de São Paulo (PUC-SP) e doutorando em estágio docente no Instituto de Economia da Universidade Estadual de Campinas (Unicamp). Presidente do Centro de Estudos e Memória da Juventude (CEMJ).

E-mail: euzebiojorge@gmail.com

** Mestre e doutorando em Direito Constitucional pela Pontifícia Universidade Católica de São Paulo (PUC-SP). Advogado em São Paulo.

E-mail: marcio.meinberg@gmail.com

Texto recebido em maio de 2020; aprovado em junho de 2020. 
ABDALA, Vitor. Taxa de desemprego no país fecha 2017 em 12,7\%; população desocupada cai 5\%. Agência Brasil, Rio de Janeiro, 31 jan. 2018. Disponível em: <https:// agenciabrasil.ebc.com.br/economia/noticia/2018-01/taxa-de-desemprego-no-pais-fecha-2017-em-127>. Acesso em: 17 maio 2020.

ABÍLIO, Ludmila Costhek. Uberização: do empreendedorismo para o autogerenciamento subordinado. Psicoperspectivas, Valparaíso, v. 18, n. 3, nov. 2019.

BALTAR, Paulo Eduardo de A.; SOUEN, Jacqueline A.; CAMPOS, Guilherme C. de Souza. Emprego e distribuição da renda. In: CARNEIRO, Ricardo; BALTAR, Paulo; SARTI, Fernando (Org.). Para além da política econômica. São Paulo: Editora Unesp Digital, 2018.

BARROS, Alerrandre. Desemprego aumenta para 11,6\% no trimestre encerrado em fevereiro. Agência IBGE Notícias, Rio de Janeiro, 31 mar. 2020. Disponível em: <https://agenciadenoticias.ibge.gov.br/agencia-noticias/2012-agencia-de-noticias/noticias/27260-desemprego-aumenta-para-11-6-no-trimestre-encerrado-em-fevereiro>. Acesso em: 17 maio 2020.

BRASIL. Consolidação das Leis do Trabalho. Decreto-lei n 5.452, de $1^{\circ}$ de maio de 1943. Disponível em: <www.planalto.gov.br/ccivil_03/decreto-lei/del5452.htm>. Acesso em: 17 maio 2020.

BRASIL. Lei $\mathbf{n}^{\circ} \mathbf{6 . 0 1 9 / 7 4}$, de 3 de janeiro de 1974. Disponível em: <www.planalto.gov.br/ ccivil 03/leis/l6019.htm>. Acesso em: 17 maio 2020.

BRASIL. Lei $\mathbf{n}^{\circ} \mathbf{8 . 1 7 7 / 9 1}$, de $1^{\circ}$ de março de 1991. Disponível em: <www.planalto.gov.br/ ccivil 03/leis/L8177.htm>. Acesso em: 17 maio 2020.

BRASIL. Lei $\mathbf{n}^{\circ} \mathbf{8 . 2 1 3}$, de 24 de julho de 1991. Disponível em: <www.planalto.gov.br/ccivil 03/leis/l8213cons.htm>. Acesso em: 17 maio 2020.

BRASIL. Lei $\mathbf{n}^{\circ}$ 12.529/11, de 30 de novembro de 2011. Disponível em: <www.planalto. gov.br/ccivil 03/ ato2011-2014/2011/lei/l12529.htm>. Acesso em: 17 maio 2020.

BRASIL. Lei $\mathbf{n}^{\circ}$ 13.467/17, de 13 de junho de 2017. Disponível em: <www.planalto.gov.br/ ccivil 03/ ato2015-2018/2017/lei//13467.htm>. Acesso em: 17 maio 2020.

BRASIL. Lei $\mathbf{n}^{\circ} \mathbf{1 3 . 8 7 4 / 1 9}$, de 20 de setembro de 2019. Disponível em: <www.planalto.gov. br/ccivil 03/ ato2019-2022/2019/lei/L13874.htm>. Acesso em: 17 maio 2020.

BRASIL. Medida Provisória $\mathbf{n}^{\circ}$ 905/20, de 11 de novembro de 2019. Disponível em: <www.planalto.gov.br/ccivil_03/_ato2019-2022/2019/Mpv/mpv905.htm>. Acesso em: 17 maio 2020.

BRASIL. Medida Provisória n 927/20, de 22 de março de 2020. Disponível em: <www.planalto.gov.br/ccivil 03/ ato2019-2022/2020/Mpv/mpv927.htm>. Acesso em: 17 maio 2020. 
BRASIL. Medida Provisória $\mathbf{n}^{\circ} \mathbf{9 2 8} / \mathbf{2 0}$, de 23 de março de 2020. Disponível em: <www.planalto.gov.br/ccivil 03/ ato2019-2022/2020/Mpv/mpv928.htm>. Acesso em: 17 maio 2020.

BRASIL. Medida Provisória n 936/20, de $1^{\circ}$ de abril de 2020. Disponível em: swww.planalto.gov.br/ccivil 03/ ato2019-2022/2020/mpv/mpv936.htm >. Acesso em: 17 maio 2020.

DE STEFANO, Valerio. The rise of the "just-in-time workforce": on-demand work, crowdwork and labour protection in the "gig-economy". Genebra: International Labour Office, 2016.

FERREIRA, Adriana Nunes. Desemprego e teoria macroeconômica. Texto para Discussão, n. 231. Campinas: IE-Unicamp, maio 2014.

GOMES, Orlando; GOTTSCHALK, Elson Guimarães. Curso de direito do trabalho. 19. ed. Rio de Janeiro: Forense, 2011.

JAKITAS, Renato. 12h por dia, 7 dias por semana, R\$ 936: como é pedalar fazendo entregas por aplicativo. Estadão, 15 set. 2019. Disponível em : <www.estadao.com.br/infograficos/economia,12h-por-dia-7-dias-por-semana-r-936-como-e-pedalar-fazendo-entregas-por-aplicativo,1034668>. Acesso em: 17 maio 2020.

LEMOS, Vinícius. O cadeirante que entrega comidas por aplicativos na avenida Paulista. BBC News Brasil, São Paulo, 18 fev. 2020. Disponível em: <www.bbc.com/portuguese/ brasil-51551861>. Acesso em: 17 maio 2020.

MENDONÇA, Heloísa; OLIVEIRA, Regiane. Entenda as novas regras que reduzem o combate ao trabalho escravo. El País, São Paulo, 20 out. 2017. Disponível em: <https://brasil. elpais.com/brasil/2017/10/19/politica/1508447540_501606.html>. Acesso em: 17 maio 2020.

MIGLIOLI, Jorge. Acumulação de capital e demanda efetiva. 1979. Tese (Livre-docência em Economia) - Instituto de Filosofia e Ciências Humanas, Universidade de Campinas, Campinas, 1979. Disponível em: <www.repositorio.unicamp.br/handle/REPOSIP/281353>. Acesso em: 3 jul. 2020.

OLIVEIRA, Tiago. Trabalho e padrão de desenvolvimento: uma reflexão sobre a reconfiguração do mercado de trabalho. 2015. Tese (Doutorado em Economia) — Instituto de Economia, Universidade de Campinas, Campinas, 2015.

SOUSA, Euzébio Jorge Silveira de. O desemprego da juventude no Brasil em crise. Juventude.br, São Paulo, v. 1, p. 66, 2018.

Pensamento neoclássico e mercado de trabalho: fundamentos teóricos por trás da reforma trabalhista. Rio de Janeiro: XV Encontro Nacional da Abet, 2017. 